\title{
Investigation of the well-dispersed magnetorheological oil-based suspension with superparamagnetic nanoparticles using modified split Hopkinson pressure bar
}

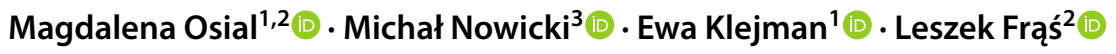

Received: 30 April 2020 / Revised: 8 September 2021 / Accepted: 22 November 2021 / Published online: 2 December 2021

(c) The Author(s) 2021

\begin{abstract}
Magnetorheological (MR) fluids are classified as smart materials whose viscoplastic characteristics change under the magnetic field. They are widely applied for dynamic energy dissipation due to their rapid thickening under the external magnetic field. In this work, the core-shell suspension of superparamagnetic iron oxide-based nanoparticles was synthesized and dispersed in silicone oil. Much effort has been made to prepare suspension meeting requirements of MR fluid. The experimental squeezing flow response was studied using a modified split Hopkinson pressure bar (SHPB) with various shear rates. Tests with modified SHPB show that MR fluid rapidly responds to the compression thickening and forming chain-like structures. MR fluid dissipates the energy generated during compression stress tests. This study presents a simple and cost-effective synthesis way suitable for MR fluid formation for its dynamic energy dissipation application.
\end{abstract}

Keywords SPION · Magnetorheological fluid · Split Hopkinson pressure bar · High strain rate $\cdot$ Dynamic behaviour

$\begin{array}{ll}\text { Abbreviations } \\ A_{I} & \text { Cross-section area } \\ A_{T} & \text { Cross-section area of the hollow } \\ C_{0} & \text { Speed of a stress wave in the bar } \\ D & \text { Diameter of the bar } \\ D_{S 0} & \text { Diameter of specimen } \\ e(t) & \text { Axial strain } \\ e_{I}(t) & \text { Incident wave } \\ e_{T}(t) & \text { Reflected wave } \\ e_{R}(t) & \text { Transmitted wave } \\ E & \text { Young modulus } \\ \text { FT-IR } & \text { Fourier transformed infrared spectroscopy } \\ l_{0} & \text { Length of the specimen } \\ \text { MR } & \text { Magnetorheological } \\ \end{array}$

Magdalena Osial and Leszek Frąś contributed equally to this work.

Magdalena Osial

mosial@chem.uw.edu.pl

1 Faculty of Chemistry, University of Warsaw, Pasteura 1, 02-093 Warsaw, Poland

2 Institute of Fundamental Technological Research of the Polish Academy of Science, Pawińskiego 5B, 02-106 Warsaw, Poland

3 Institute of Metrology and Biomedical Engineering, Warsaw University of Technology, Boboli 8, 02-525 Warsaw, Poland
MRF Magnetorheological fluid

$\dot{\varepsilon}_{n s}(t) \quad$ Nominal strain rate

NP Nanoparticle

OA Oleylamine

$\sigma_{n S}(t) \quad$ Nominal strain

SEM Scanning electron microscopy

SHPB Split Hopkinson pressure bar

SPION Superparamagnetic iron oxide nanoparticle

SPION@OA Superparamagnetic iron oxide nanoparticle capped with oleylamine

TEM Transmission electron microscopy

TGA Thermogravimetry

\section{Introduction}

Magnetorheological (MR) fluids are categorized as smart materials, and they are one of the most functional fluids changing rheological properties under the application of the external magnetic field (Acharya et al. 2020). Such field-responsive fluids can reverse their viscosity forming a chain-like structure (Ashour et al. 1996, Muhhamed et al. 2006), while without magnetic field MR fluid behaves like Newtonian (Bica 2006). Formation of the solid-like structures of fibril shapes due to the dipole-dipole interactions between particles under the adjusted magnetic field leads 
to the increased viscosity and strength of the fluid with stable shear resistance (Susan-Resiga et al. 2012, An 2017). Such unique magnetorheological properties of MR fluids open possibilities for their application in many fields, especially in mechanical devices like valves, dampers, clutch or brakes to reduce different vibrations (Kciuk and Turczyn 2006, Pręgowska et al. 2013, Ashtiani et al. 2015, Kumar and Kumar 2015). MR fluids are usually made of ferromagnetic colloidal suspension dispersed in liquid media like oil (Premalatha et al. 2012, Galindo-Gonzalez et al. 2016, Zhu et al. 2019). Although MR fluids reveal the ability to respond rapidly to the magnetic field, they tend to sediment decreasing their long-term stability (Wereley et al. 2006, Park et al. 2009). For that reason, much progress has been made towards improving the stability of MR fluids, including fluids differing from iron particles-based have been investigated (Seo et al. 2016, Guo et al. 2018).

Among various ferromagnetic materials, magnetic nanoparticles (NPs) based on iron oxide have shown high magnetization saturation and small hysteresis values, which makes them a promising material for MR fluids (Espin et al. 2005, Rabbani et al. 2019). Despite the wide application of the micron-sized particles in classical MR fluids, recent studies show the high potential of nano-sized particles in MR fluid preparation (Chae et al. 2015, Wu et al. 2016, Saha et al., 2019).

Within our studies, even very small particles obtained size up to $20 \mathrm{~nm}$ revealing superparamagnetic modified stabilized with organic molecules can be applied as the magnetorheological fluid.

In this work, MR fluid based on the core-shell superparamagnetic iron oxide nanoparticles (SPIONs) capped with oleylamine (OA) known as an effective stabilizing agent for various nanoparticles, including magnetic particles, was synthesized and investigated (Peng et al. 2006). The synthesis was performed with a simple and cost-effective coprecipitation technique (Gawęda et al. 2020, Rashid et al. 2020). The suspension was dispersed in silicone oil, and several methods were used for the investigation of the colloid properties. Additional experiments aimed at measuring the dynamic energy dispersion have been carried using split Hopkinson pressure bar (SHPB) (Lim et al. 2010a), being a technique widely used for testing the strain compression of various materials having industrial application (Shim and Mohr 2009, Lim et al. 2010b). Within SHPB measurements, the response of colloidal SPION@OA suspension under high strain rates (Frąs 2015) and determination of the time needed for the transition were investigated (Lim et al. 2010b). So far, our attention has been paid to the study of stress relaxation of our MR fluid under stress to provide information towards the description of the mechanical properties of our fluid. Additionally, the classical bar-bar system (Frąś and Pęcherski 2018) was improved and substituted with a bar-hollow system, improving the signal detection for even minimal rheological changes of the colloidal under stress.

\section{Experimental}

\section{Chemicals}

Iron (III) chloride hexahydrate $\mathrm{FeCl}_{3} \cdot 6 \mathrm{H}_{2} \mathrm{O}$ Aldrich ACS reagent $97 \%$ and iron (II) chloride tetrahydrate $\mathrm{FeCl}_{2} \cdot 4 \mathrm{H}_{2} \mathrm{O}$ puriss p.a. $\geq 99 \%$ (RT) were supplied from Sigma-Aldrich. Twenty-five percent ammonia solution $\mathrm{NH}_{4} \mathrm{OH}$ was provided from POCH. Deionized water with resistivity $18.2 \mathrm{M} \Omega \mathrm{cm}$ at $25{ }^{\circ} \mathrm{C}$ was obtained using the Milli-Q ultra-pure water filtering system from Merck. Ethanol was purchased from Chempur with $96 \%$ analytical grade. Acetone was purchased from POCH with commercial grade. Synthesized SPIONs were modified with oleylamine puriss $\geq 98 \%$ obtained from Sigma-Aldrich. The silicone oil for high temperatures was purchased from ACROS Organics.

\section{Synthesis and modification of SPIONs}

Iron oxide nanoparticles were synthesized with a co-precipitation method at room temperature from the solution containing $5.40 \mathrm{~g}$ of $\mathrm{FeCl}_{3} * 6 \mathrm{H}_{2} \mathrm{O}$ and $1.99 \mathrm{~g}$ of $\mathrm{FeCl}_{2} * 4 \mathrm{H}_{2} \mathrm{O}$ in $100 \mathrm{~mL}$ of water in a glass beaker. Next, a $25 \% \mathrm{NH}_{4} \mathrm{OH}$ aqueous solution was added as a precipitation agent. Synthesis of iron oxide nanoparticles was carried out for $5 \mathrm{~min}$ at $\mathrm{pH} 10$, with mechanical stirring $300 \mathrm{rpm}$. After synthesis, particles were separated from the solution on the magnet and rinsed several times with Milli-Q water until neutral $\mathrm{pH}$. Next, the NPs were washed several times with ethanol and acetone, and $500 \mu \mathrm{L}$ of oleylamine was added as a capping agent. Such compounds are widely used as an effective capping agent for the improvement of the stability of colloids ( $\mathrm{Lu}$ et al. 2016). After OA addition, the suspension was mechanically mixed with $500 \mathrm{rpm}$ for $30 \mathrm{~min}$ and then placed in the ultrasonic bath for $10 \mathrm{~min}$ to make the mixture evenly. After OA capping nanoparticles were collected on a magnet and ethanol was removed.

Two different kinds of volume fractions (65\% and $75 \%$ OA capped particles content vs oil fraction) were prepared by mechanical mixing with 500 rpm for 60 min of SPION@ OA with silicone oil at room temperature. Then, obtained suspension was completely uniform, and no additives were needed. Figure 1 shows the synthesis from (a) solution containing a source of iron (II) and (III) ions, (b) nanoparticles collected on a magnet after ammonia solution addition and stirring, (c) nanoparticles orienting along the direction of the magnetic field in water and (d) SPION@OA in oil in the presence of the magnetic field. 
Fig. 1 Preparation of MR fluid a solution with a source of $\mathrm{Fe}(\mathrm{II})$ and $\mathrm{Fe}(\mathrm{III})$ ions before ammonia solution addition, $\mathbf{b}$ nanoparticles collected on the magnet in water, $\mathbf{c}$ MR fluid behaviour in the presence of the magnetic field, and $\mathbf{d}$ the MR fluid attracted by magnet

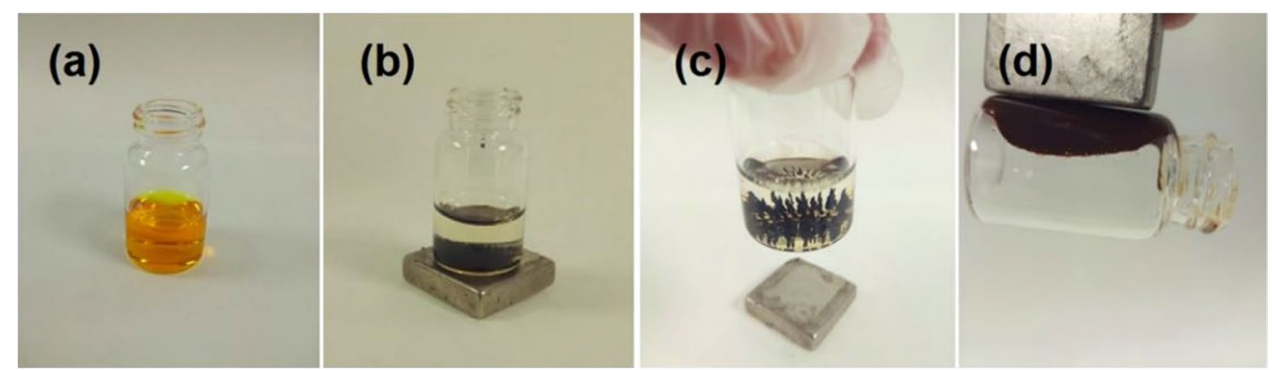

\section{Methods}

The size and shape of synthesized SPIONs were studied with transmission electron microscopy (TEM)_EF-TEM, Zeiss Libra 120 Plus, Stuttgart, Germany, operating at $120 \mathrm{kV}$, and scanning electron microscopy (SEM)-Merlin, ZEISS, Stuttgart, Germany.

The presence of organic compounds on the SPIONs surface was investigated by FT-IR spectroscopy with Nicolet 8700 Spectrometer (Thermo Scientific).

Thermogravimetric analysis (TGA) was performed with TGA Q50 (TA Instruments), New Castle, USA, under a nitrogen atmosphere.

The magnetic behaviour of samples was investigated with QD vibrating sample magnetometer (VSM) over the magnetic field range from -2.0 to $+2.0 \mathrm{~T}$ in the $100 \mathrm{~K}$ and $300 \mathrm{~K}$ stabilized to the accuracy of about $0.01 \mathrm{~K}$.

The microscopic images of MR fluid were examined through Olympus optical microscope BX 41-TF. The images were taken with the Olympus digital camera. The rheological properties were studied with and without a magnetic field using a parallel plate type system at room temperature, with the sinusoidal change of current.

Viscosity and shear stress curves of the investigated samples were measured on the specially constructed test stand, which main component was heavily modified rotary rheometer (Rheotest 2.1, Germany). Its torquemeter was equipped with high precision ADC, and data acquisition software was written in LabVIEW. Furthermore, it was calibrated with $30 \mathrm{~Pa}^{*}$ s silicone viscosity standard (AMETEK Brookfield, Germany) obtaining $+-0.1 \mathrm{~Pa}^{*} \mathrm{~s}$ measurement uncertainty. Axial magnetic field was provided by either current controlled coil (up to $50 \mathrm{mT}$ ) or specially designed ring permanent magnets (100 and $150 \mathrm{mT}$ ). Magnetic field was measured with teslameter (Lakeshore 475, USA).

The dynamic behaviour of samples was tested with its laboratory stand of split Hopkinson pressure bar setup. SHPB was made with 7075 alloy aluminium bar $1000 \times 20 \mathrm{~mm}$ as an incident bar and hollow as a transmitted bar with the wall thickness $2 \mathrm{~mm}$ (see Fig. 2). The incident bar is working as a quarter bridge, but a transmitted bar is connected with a full-bridge sensor system. The signal from strain gauges is amplified by $400 \mathrm{~V} / \mathrm{V}$. The laboratory test stand is using the coil, with inner diameter $30 \mathrm{~mm}$ and length $50 \mathrm{~mm}$ having 80 turns of the wire with the final resistance $180 \Omega$. The power line was supplied with EA-PS 8360-30, where maximal direct voltage value is $360 \mathrm{~V}$ and the current is $2 \mathrm{~A}$ and it can generate $150 \mathrm{mT}$ magnetic field, what is more, the SHPS is modified with the hollow (11 at Fig. 2).

The application of bar-hollow system instead of the classical bar-bar system improves mechanically recorded signals, allowing for a determination of even minimal deformations of tested colloidal suspension. The applied strain rate varied from $4.42 \cdot 10^{3}$ to $1.18 \cdot 10^{4} \mathrm{~s}^{-1}$.

\section{Results}

\section{Morphology, magnetic and spectroscopic properties}

The shape and size of bare SPIONs and SPION@OA was investigated with transmission electron microscopy. As can be seen at Fig. 3a, SPIONs have a well-defined

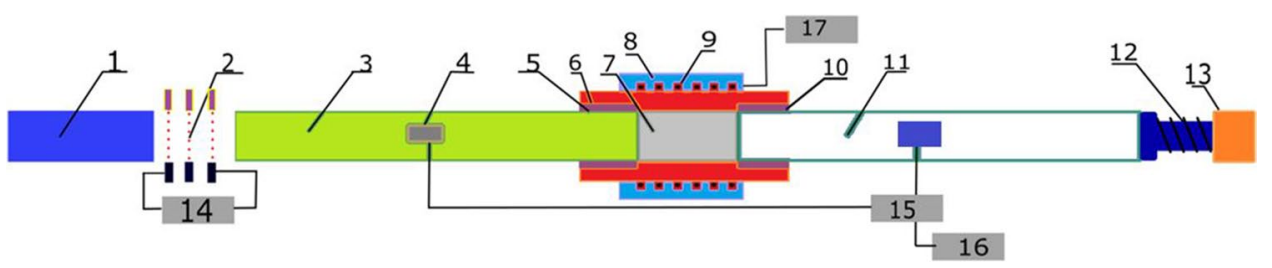

Fig. 2 Scheme of Hopkinson bar used for dynamic evaluation of synthesized MR fluid. (1) Striker, (2) laser sensor to measure velocity, (3) incident bar, (4) strain gauges, (5) sealing, (6) deformable hose,
(7) MR fluid, (8) coil cover, (9) coil, (10) sealing, (11) transmitter bar-hollow, (12) spring, (13) momentum trap, (14) velocity measure system, (15) signal amplifier, (16) oscilloscope 
Fig. 3 a TEM images of bare SPION before surface modification, $\mathbf{b}$ TEM image of SPIONs capped with oleylamine, c SEM image of SPIONs capped with oleylamine (a)

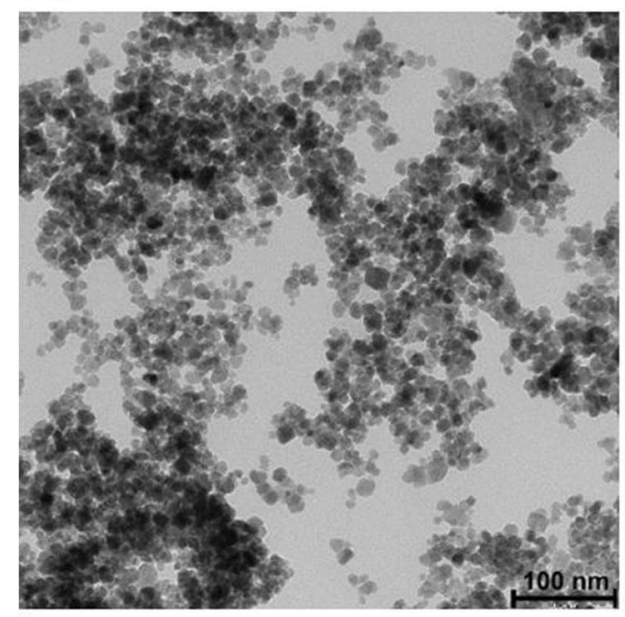

(b)

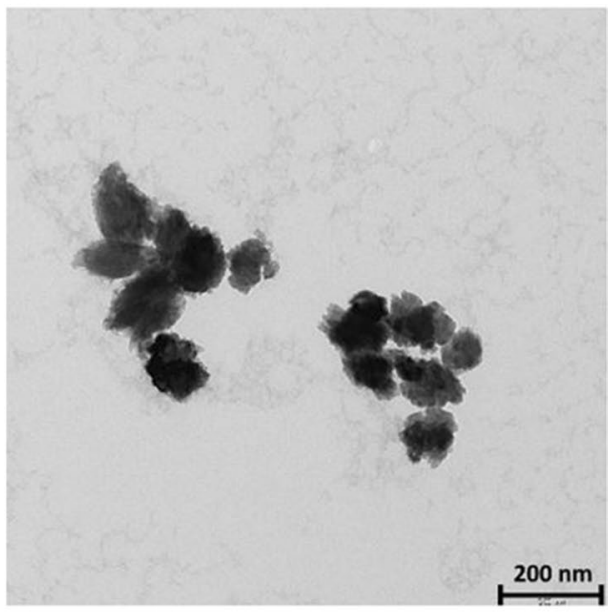

(c)

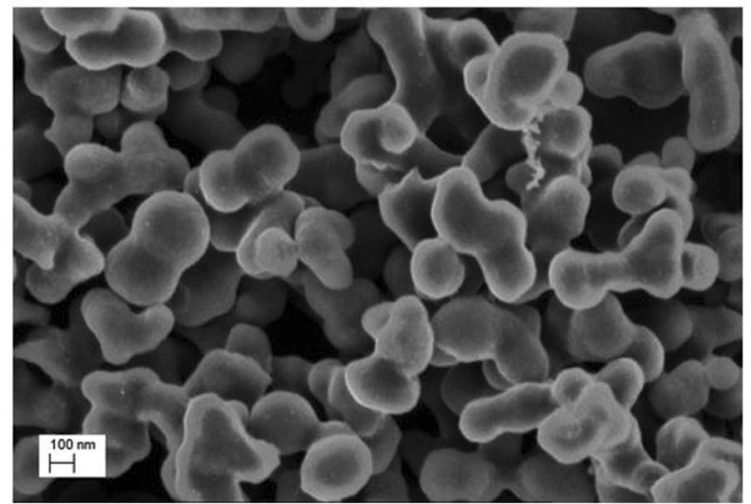

spherical shape with a measured average length axis of 10-15 nm, while after oleylamine capping nanoparticles agglomerate forming 100-130 nm diameter spheres with similar shape and size (see Fig. 4b). Additionally, scanning electron microscopy was used for the determination of the shape and size of SPION@OA (see Fig. 4c).

The spectroscopic analysis shows that the magnetic core is effectively covered with oleylamine shell. As can be seen (a)

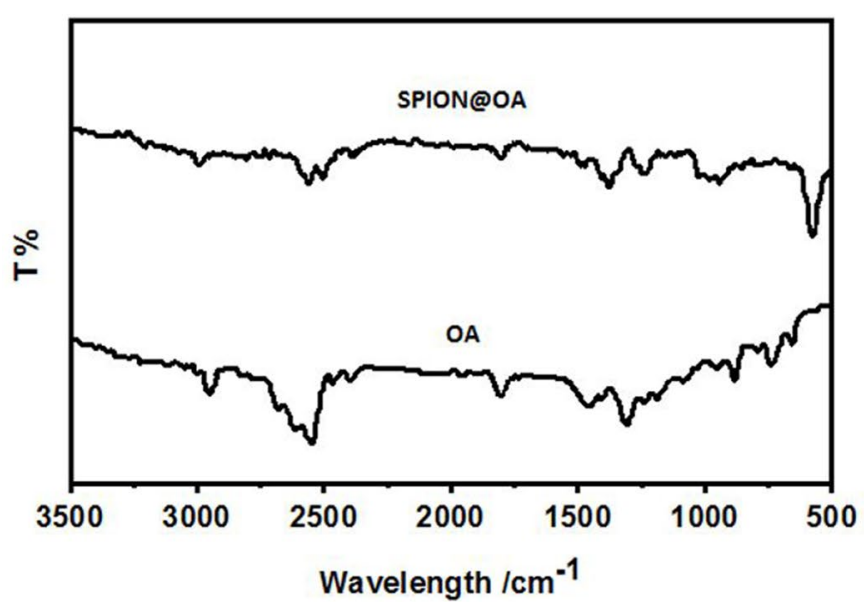

(b)

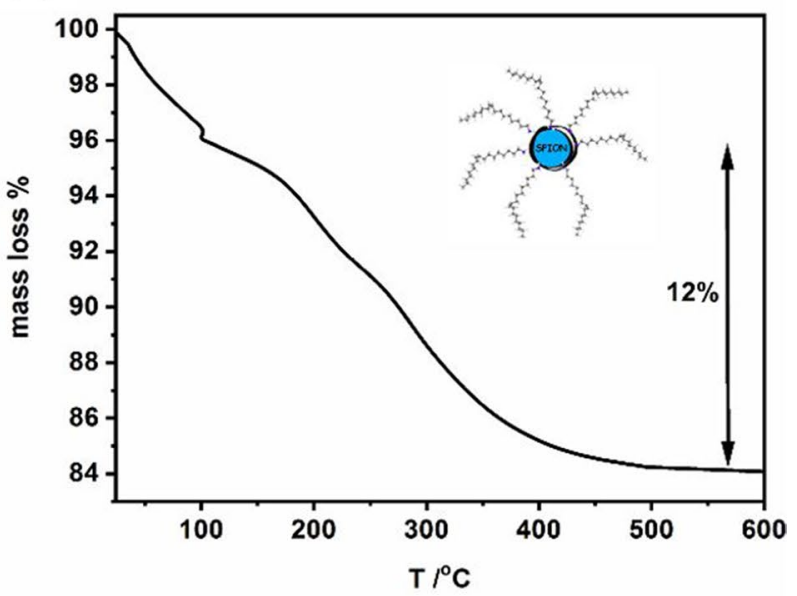

Fig.4 a FT-IR spectra of SPION@OA and OA and b TGA curve for SPION@OA 
at Fig. 4a, FT-IR spectra recorded for pure oleylamine and SPIONs capped with OA are similar, confirming that SPIONs are successfully covered with OA. Recorded spectra are in agreement with the literature data (Zhang et al. 2007, Kuman et al. 2014).

The band recorded at $590 \mathrm{~cm}^{-1}$ is characteristic for stretching $\mathrm{Fe}-\mathrm{O}$ vibration at iron oxide particles. The signal around $1610 \mathrm{~cm}^{-1}$ is assigned to the $\mathrm{N}-\mathrm{H}$ bending and $\mathrm{NH}_{2}$ scissoring motion. For SPION@OA sample, the band at that region is much smaller than for OA measured separately indicating adsorption of OA on the surface of SPIONs. Both spectra reveal characteristic bands of terminal methyl asymmetric in-plane $\mathrm{C}-\mathrm{H}$ stretching at $2900 \mathrm{~cm}^{-1}$ and asymmetric $\mathrm{C}-\mathrm{H}$ stretching at $2850 \mathrm{~cm}^{-1}$. The shift of bands for the SPION@OA sample may correspond to the constraint of the molecular motions due to the formation of close-packed layers of oleylamine on the SPIONs (Wang et al. 2014).

The thermogravimetry analysis was performed in the temperature range from ambient to $600^{\circ} \mathrm{C}$, with a heating rate of $10^{\circ} \mathrm{C} / \mathrm{min}$. Measurement was performed under the nitrogen atmosphere (see Fig. 4b). The initial mass loss below $100^{\circ} \mathrm{C}$ corresponds to the elimination of water molecules adsorbed on the surface of SPIONs@OA. The following a drop of the mass is ascribed to degradation of the oleylamine degradation indicating $12 \%$ of OA on the surface of SPIONs.

The magnetic property of prepared material is a significant index influencing the magnetorheological property of MR fluid. Studies of as-synthesized iron oxide nanoparticles with magnetometry reveal the superparamagnetic behaviour of samples (see Fig. 5). The saturation magnetization of SPIONs was about $91 \mathrm{emu} / \mathrm{g}$ at $100 \mathrm{~K}$ and $82 \mathrm{emu} / \mathrm{g}$ at $300 \mathrm{~K}$ with low coercivity, which corresponds to data for SPIONs prepared in different conditions (Osial et al. 2018).

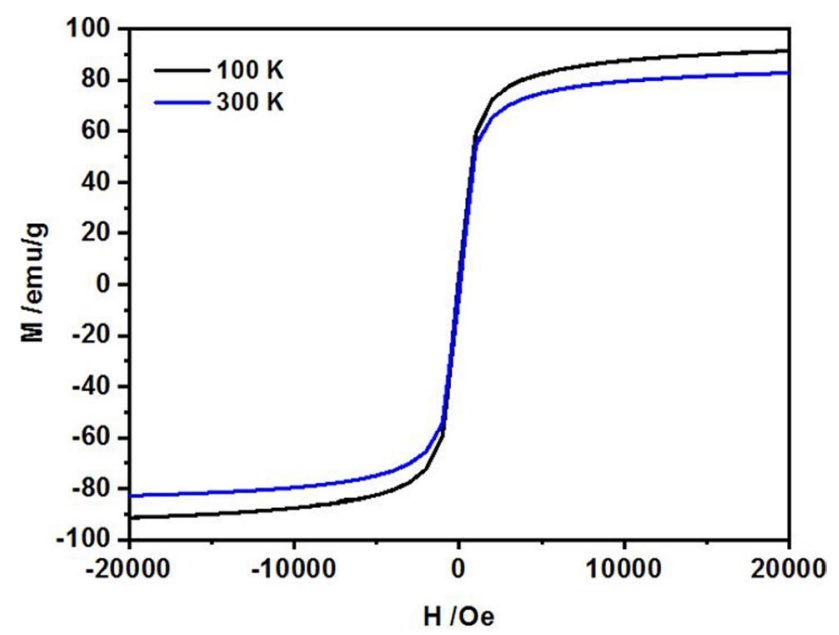

Fig. 5 Magnetization isotherms for SPIONs measured at $100 \mathrm{~K}$ and $300 \mathrm{~K}$

\section{Stability of MR fluid}

The stability of MR suspension depends on the content of iron oxide nanoparticles in the suspension. In general, the sedimentation of particles dispersed in the liquid is not desirable property, especially in the case of MR fluid application for dynamic energy dissipation. Sedimentation tests were performed on two samples to compare the stability (see Fig. 6), and the sedimentation rate was calculated using Eq. 1:

Sedimentationpercentage $(S)=\frac{\text { Volumeofsupernatantfluid }}{\text { Totalvolumeofthefluid }} \times 100 \%$

Sedimentation can be caused by the density mismatch between SPIONs@OA and oil, although the stability is much higher in comparison to other liquids, where the deposition reaches even 60\% (Zhang et al. 2009, Jinaga et al. 2019, Kumar et al. 2019).

The suspension of SPIONs@OA in silicone oil was also investigated with an optical microscope showing homogeneous dispersion without and under a magnetic field (see Fig. 7). The experiments were performed on a glass side, and the optical micrographs were taken in transmission mode. The applied magnetic field was about $10 \mathrm{mT}$. The direction of the current was changed with a sinusoid direction and the suspension structure was measured in a droplet sample having volume $10 \mu \mathrm{L}$ diluted twice with oil was subjected to the magnetic field of strength using dual-mode coil. Initially, without the magnetic field (Fig. 7a), the nanoparticles in the suspension are dispersed randomly on the microscopic glass. When the magnetic field is induced, the NPs spontaneously start to form chain-like structures revealing MR properties (Fig. 7b-h) (Wang et al. 2020). Suspension quickly reorganized into

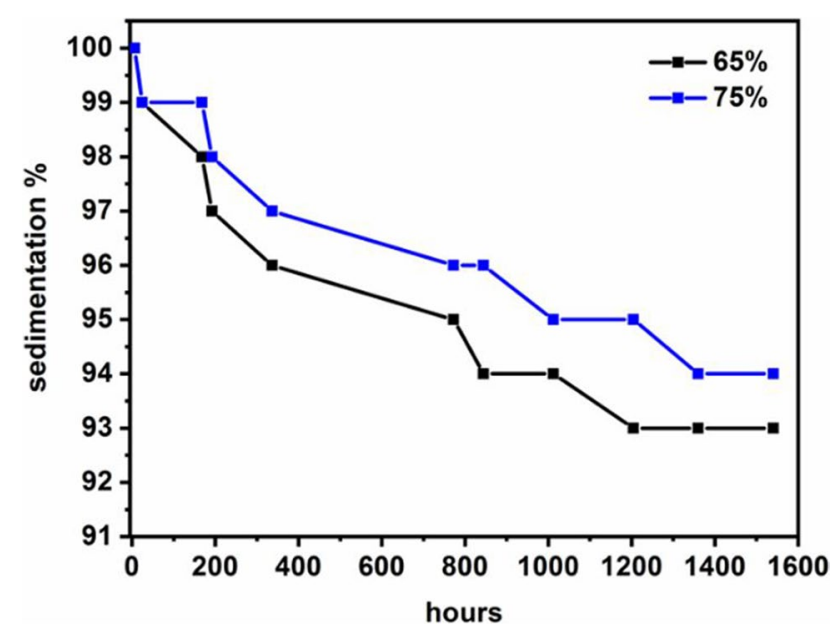

Fig. 6 Sedimentation of synthesized MR fluid in the function of time 
Fig. 7 The silicon oil-based suspension (65\% volume ratio) a without a magnetic field, $\mathbf{b}-\mathbf{g}$ under magnetic field changing direction, and $\mathbf{h}$ without a magnetic field, with the scale bar of $100 \mu \mathrm{m}$ (a)

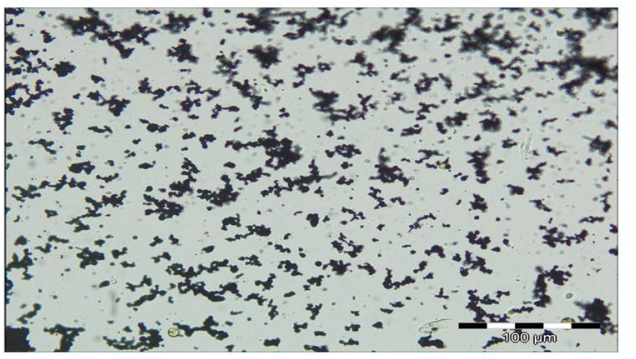

(c)

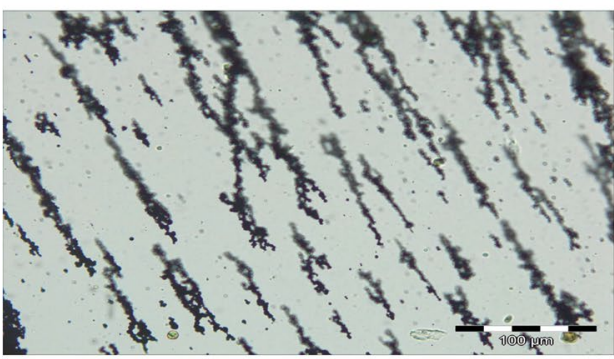

(e)

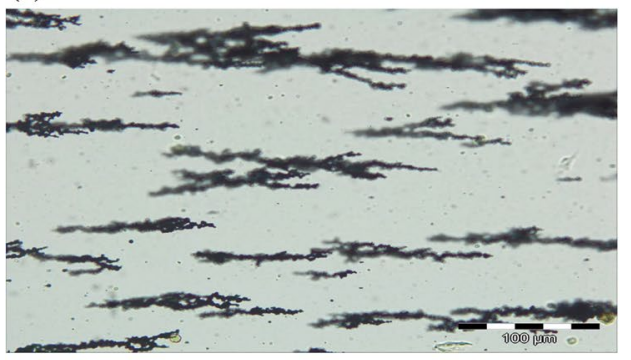

(g)

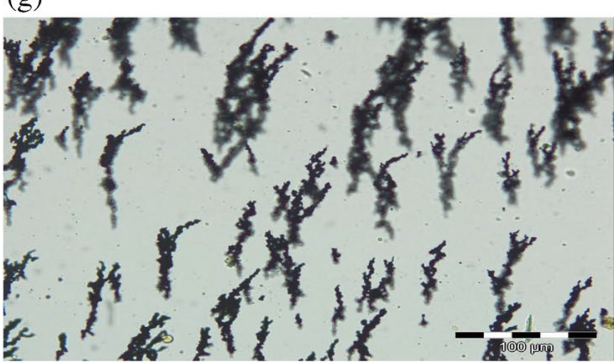

(b)

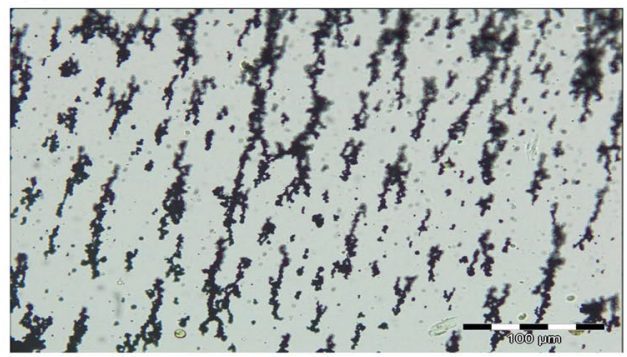

(d)

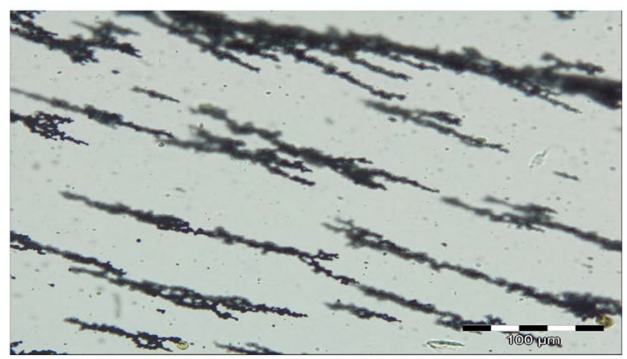

(f)

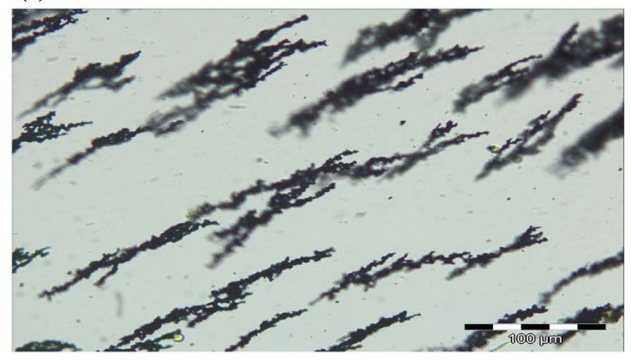

(h)

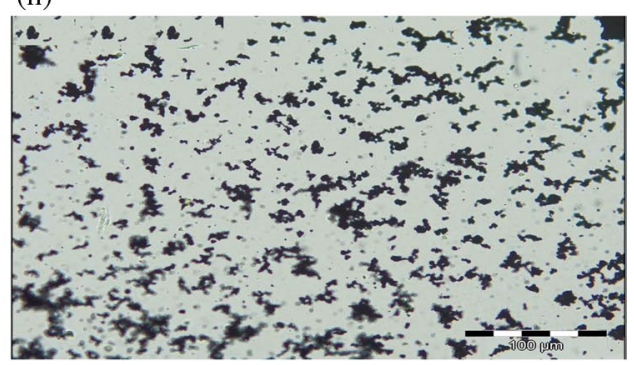

particle-rich zones orienting along with the direction of the magnetic field.

Application of the magnetic field causes agglomeration of the particles, which form the parallel zones. They rotate following the direction of the magnetic field forming chain-like structures, while when the magnetic field is off, the agglomerates disperse like before its application.

\section{Viscosity studies}

Additionally, the viscosity of as-synthesized MR fluid was tested within the concentric cylinder rotational viscometer, using $100 \mathrm{~mL}$ of MR fluid. Measurements were performed in the room temperature and without the magnetic field. As can be seen in Fig. 8, the viscosity of the as-synthesized MR fluid decreases with the growth of the shear rate. Viscosity of MRF for higher content (about 75\%) of solid nanoparticles is about $2 \mathrm{~Pa}^{*} \mathrm{~s}$ higher than for lesser one (about $65 \%$ NPs).

\section{Dynamic behaviour}

Following studies of colloidal suspensions with $65 \%$ and 75\% SPION@OA content in silicone oil were focused on the investigation of their viscoelastic behaviour. The gelatin was sealed to the bars by cyanoacrylate adhesive seal and taped too. The specimen length is $2 \mathrm{~mm}$, and its diameter is $20 \mathrm{~mm}$. Our fluid was placed in the thin gelatin hose (with wall thickness max. $1 \mathrm{~mm}$ ) allowing deformation and observation of the sample behaviour during experiments. 


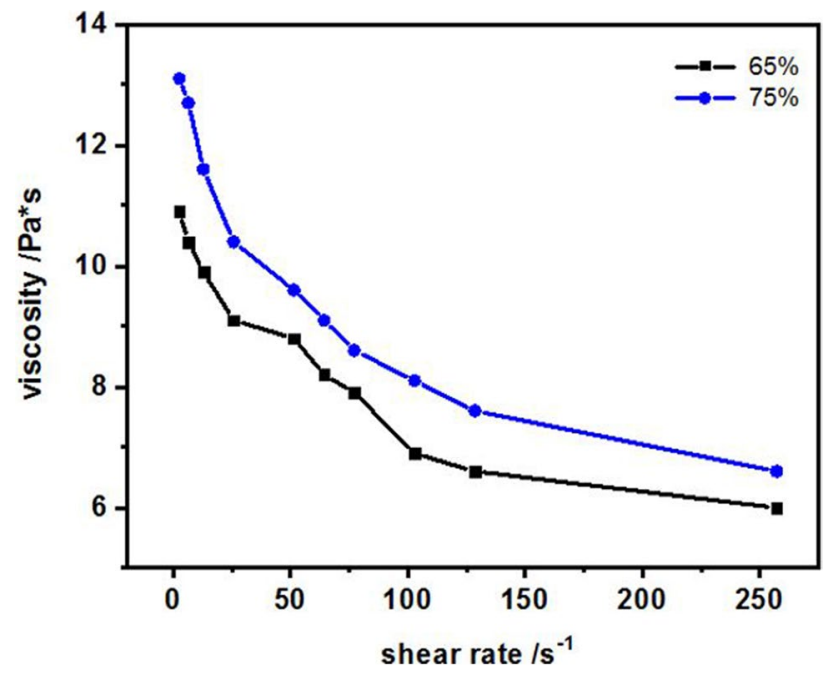

Fig. 8 The viscosity of MRF in function of shear rate

The dependence of the rearrangement of the microstructure vs applied stress was measured within a compression test. The results were obtained in which the nominal stress was permitted to vary from 0.001 to $200 \mathrm{MPa}$ in a controlled manner over the duration of $0.5 \mathrm{~ms}$. Both samples responded quickly occurring solid state under the magnetic field and liquid state without the magnetic field.

When the striker (1, Fig. 2) impacts the incident bar, then the generated stress wave is transmitted through the specimen and reaches the hollow. With the modification of the SHPR setup from the bar-bar system into the barhollow, it is possible to measure even very deformations of the tested fluid sample. Such distortions are recorded as the changes of the reflected wave (see Fig. 9). In our case, it was possible to record the wave for much smaller velocities of the striker than the literature shows (Wang et al. 2016).

The measured three waves-incident, reflected and transmitted-in the form of the axial strain $e(t)$ are described with the fundamental relation (see Eq. 2) making possible estimation of the stress and displacement. Firstly, the specimen during the test must be in the stress equilibrium.

$E\left(e_{I}+e_{R}\right) A_{I}=E e_{T} A_{T}$,

where $E$ is the Young modulus of the incident and transmitted bars. The symbol $A_{I}$ denotes the cross-section areas of the incident bar in the place of glued strain gauges and $A_{T}$ is the cross-section area of the hollow. To calculate the nominal strain, the following equations were used (Chen et al. 1999):

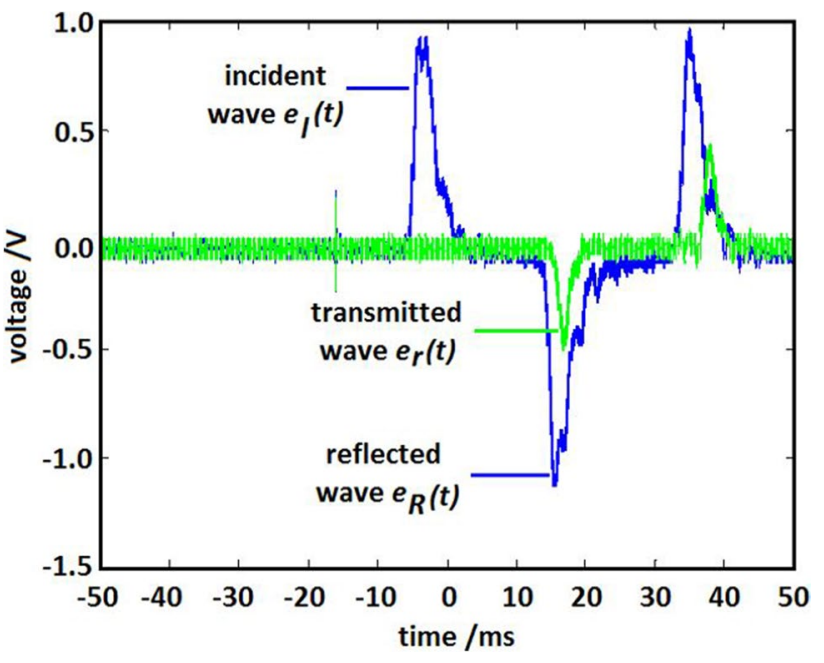

Fig. 9 The stress waves recorded by an oscilloscope

$\varepsilon_{n s}(t)=\frac{C_{0}}{l_{0}}\left(1-\frac{A_{I}}{A_{T}}\right) \int_{0}^{t} e_{I}(t) d t+\frac{C_{0}}{l_{0}}\left(1+\frac{A_{I}}{A_{T}}\right) \int_{0}^{t} e_{R}(t) d t$,

where $C_{0}$ is the speed of a stress wave in the bar and $l_{0}$ is the length of the specimen.

$\sigma_{n S}(t)=E\left(\frac{D}{D_{S 0}}\right)^{2}\left[\left(1+\frac{A_{T}}{A_{I}}\right) e(t)\right]$,

where $D$ and $D_{S 0}$ are ascribed to the diameter of the bar and specimen. Equation 5 presents the relation to calculate the nominal strain rate:

$\dot{\varepsilon}_{n s}(t)=\frac{1}{l_{0}}\left[\frac{d u_{a}(t)}{d t}-\frac{d u_{b}(t)}{d t}\right]=\frac{1}{l_{0}} \frac{d \varepsilon_{n s}(t)}{d t}$

In the beginning, when the striker hits the incident bar, the stress wave is propagating with the speed $C_{0}$ through the incident bar and compressing the material in gelatin hose. A slow increase as the nominal compressive stress occurs. The rise of the material response corresponds to the interaction of the fluid movement with the magnetic particles. Then, the MR fluid hardens, and the single peak is observed ascribed as the formation of the single chains in the fluid. After reaching the elastic limit, the curve drops, which corresponds to the dynamic recovery of the tested MR fluid. The rate of the deformation of chain-like structures changes with the speed of striker-which was changed from 8 to $16 \mathrm{~m} / \mathrm{s}$ with the magnetic field $150 \mathrm{mT}$ measured in the middle of the coil.

Maximum observed on the following curves corresponds to the steady-state regime with chain-like structures, while behind such region the curve drops slowly reaching the flow state. Measurements confirm that fluid 
material hardens under the stress wave application and flows after the relaxation.

As can be seen in Figs. 10-11, the properties of the examined fluid depend on deformation velocities. The increase of deformation speed affects the yield point increasing its value. The magnetorheological fluid responds to this stress and the characteristic wave appears due to the deformation.

As-synthesized MR fluid based on iron oxide nanoparticles reacts to sudden stress and disperses the elastic longitudinal waves. The viscoelastic properties of these functional materials are based on the structure ready to rearrangement. The deformation chain-like structure is mostly based on shifting a single iron particle and swaps them into the neighbouring chain structure. This mechanism provides the deformation of the structure. The stress values obtained for material with $65 \%$ of volume ratio are much lower than the material with $75 \%$. As can be seen in Fig. 10, the behaviour of MR fluid is dependent on the amount of magnetic nanoparticles that are responsible for viscoelastic deformation.

The best results in energy dispersion are obtained for MR fluid having $75 \%$ volume ratio for the specimen with yield
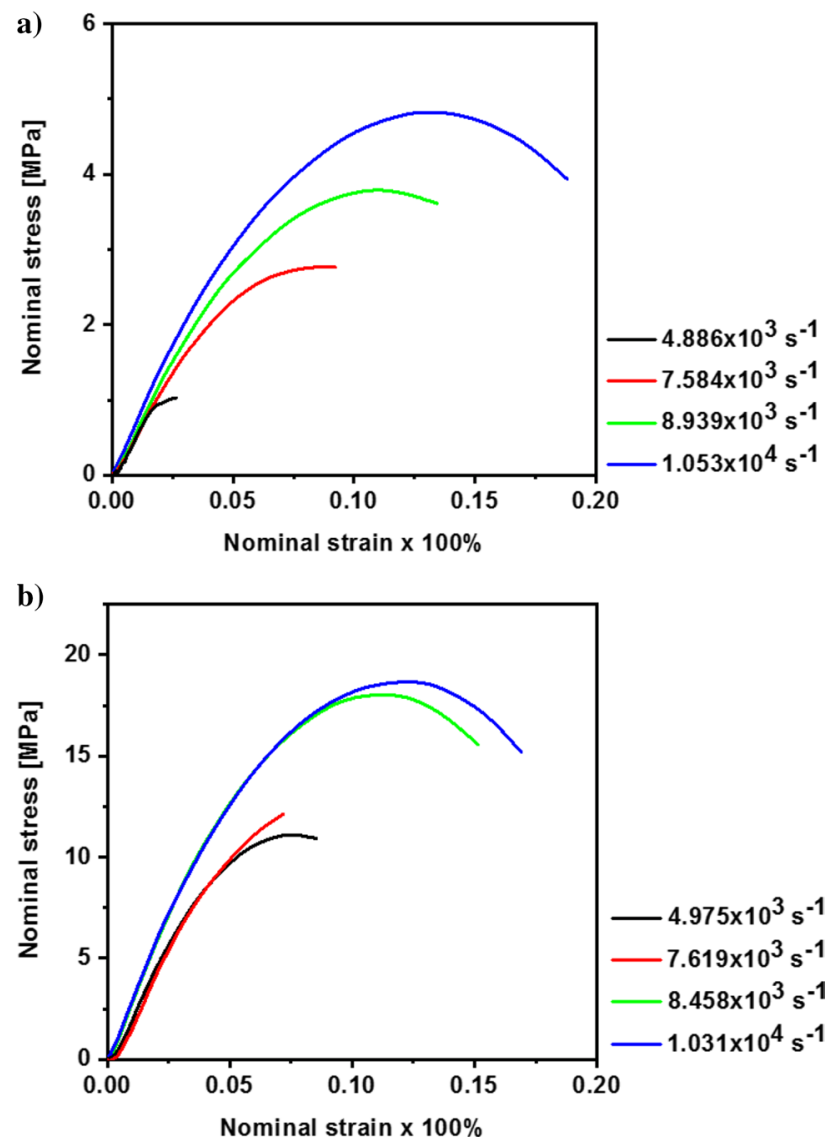

Fig. 10 Yielding for MR fluids having a 65\% volume ratio and b $75 \%$ volume ratio. Measurement was performed under the $50 \mathrm{mT}$ magnetic field
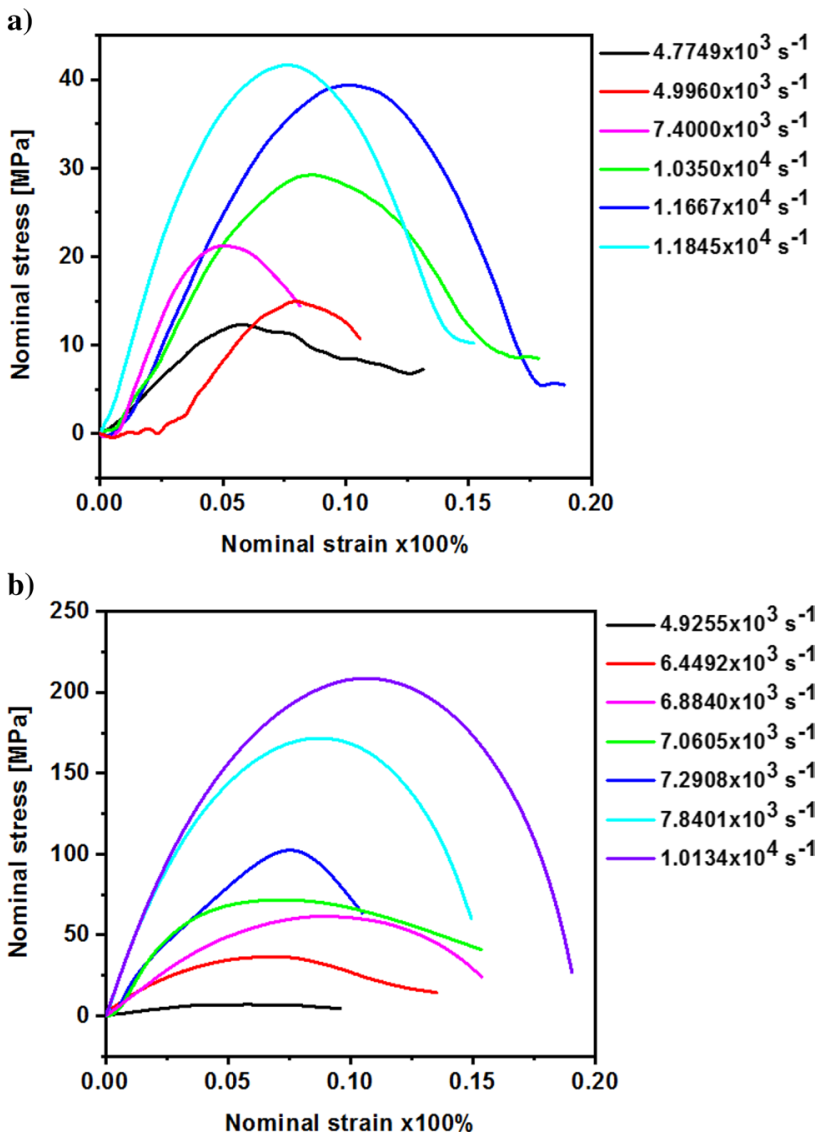

Fig. 11 Yielding for MR fluids having a 65\% volume ratio and b $75 \%$ volume ratio. Measurement was performed under the $150 \mathrm{mT}$ magnetic field

stress (the straight line crossing the stress-strain relation shifted by $0.2 \%$ relative to the elastic range) $1.2434 \cdot 10^{8} \mathrm{~Pa}$ than MR fluid having 65\% volume ratio, which reaches the yield stress $2.6883 \cdot 10^{7} \mathrm{~Pa}$. The strain rate of the specimen is closely similar, and some inaccuracies can come from another velocity of the strikers ( $15.84 \mathrm{vs} 16.04 \mathrm{~m} / \mathrm{s})$.

Our studies show that the effect of SPION@OA volume fraction on the mechanical response is observed. Results obtained for MR fluid with a $65 \%$ volume ratio are comparable with literature for hard-sphere silica particles colloidal suspensions. In comparison, a $10 \%$ rise of volume ratio improves results for even one order of magnitude (Lim et al. 2010b). In general, MR fluid is a material that has a dipole-dipole structure (Jolly et al. 1996), so in presence of a magnetic field, these structures form a chain-like structure that is far from the initial one. While the incident wave transits through the sample, the structure undergoes deformation of the structure formed by particles and the sample has no time for quick relaxation.

Additionally, commercially available MR fluid (MRF) produced by the LORD Corporation-the MRF 140-CG that contains $85.44 \%$ of ferroelements was measured with 


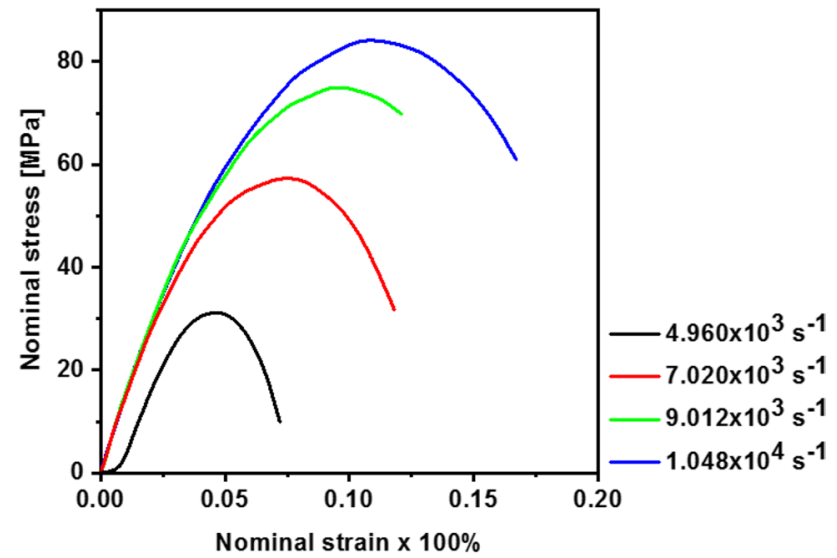

Fig. 12 Yielding for MRF 140-CG that contains $85.44 \%$ volume ratio. Measurement was performed under the $50 \mathrm{mT}$ magnetic field

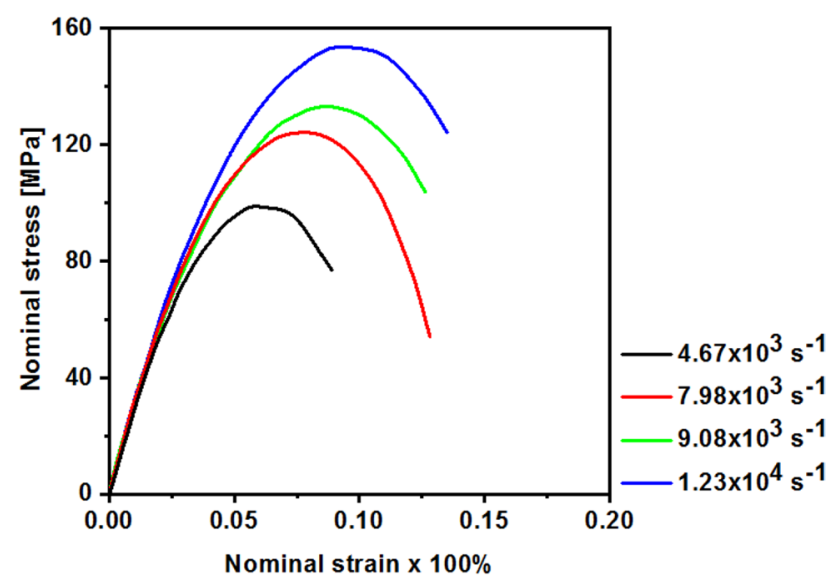

Fig. 13 Yielding for MRF 140-CG that contains $85.44 \%$ volume ratio. Measurement was performed under the $150 \mathrm{mT}$ magnetic field

the use of SHPB. Likewise, the MRF that was synthesized in this project, various striker velocities were applied. Therefore, the generated by the impact compression wave, measured by the strain gauges, allowed to calculate the nominal stress, nominal strain and strain rate. The fluid responses to this stress and the characteristic wave that appears due to the deformation are similar to the results obtained for previous samples.

Figure 12 presents an experiment performed at the magnetic field about $50 \mathrm{mT}$, while Fig. 13 shows data obtained under $150 \mathrm{mT}$.

The results confirm that MRF material solidifies similarly, where ferroelements that form chain-like structures are responsible for effective dynamic energy dissipation. According to the data obtained for commercial MRF presented in Fig. 12 and 13, the as-synthesized sample behaves slightly different than the commercial one when the velocity of the striker is low, while for the large values of velocity the efficiency is similar to the commercial MRF LORD.

The as-synthesized sample having $65 \%$ volume-ratio content has less chain-like structures, while $75 \%$ more respectively, while its susceptibility against deformation depends on the internal interactions between particles as well as the magnetic field. Under a weak magnetic field, particles form the less chain-like structure that influences the response of the sample, and as a result, lower values of stress-strain are measured. In comparison to the data that were recorded for commercially available MRF, results obtained with SHPB equipment for as-synthesized sample confirm that material can be used successfully in vibration dissipation which may have an adverse influence on mechanical devices and organisms.

Complementary to the SHPB tests, the dynamic viscosity changes and shear stress in the presence and absence of the magnetic field were investigated. Changes in the viscosity in the function of the shear rate demonstrate a non-Newtonian character for tested MR fluid. Here, the $75 \%$ colloidal suspension was tested. An increase of the viscosity is observed, where the values rise about $90 \mathrm{~Pa}^{*} \mathrm{~s}$ when the magnetic field rises from 0 to $25 \mathrm{mT}$ due to the formation of the chain-like structures in a presence of magnetic field. Significant change is also observed for the following rise of a magnetic field from 25 to $50 \mathrm{mT}$, while in $100 \mathrm{mT}$ and $150 \mathrm{mT}$ the viscosity remains similar (see Fig. 14a). These values decrease with an increase of the shear rate, which shows behaviour typical for pseudoplastic fluids with linearization of the characteristic above $3 \mathrm{~s}^{-1}$ shear rate and is typical for fluids with suspended particles. On the other hand, Fig. 14b shows the decrease of the viscosity to half of the initial value with the rise of the temperature, and with the rise of the shear rate above the value $5 \mathrm{~s}^{-1}$ it behaves similarly despite the temperature changes. Next, the shear stress was investigated in the function of shear rate. As can be seen in Fig. 14c, the changes in the shear stress values over the controlled shear rate mode increase with the increase in magnetic fields that is characteristic of the shear-thickening of the MR fluid. Following Fig. 14d presents the change of the relative viscosity in the function of shear stress. As shown below, these characteristics are monotonous for smaller values of a magnetic field, decreasing with increasing shear rate, while for higher fields they have a maximum between 1 and $3 \mathrm{~s}^{-1}$.

\section{Conclusions}

In summary, highly magnetic single crystallites based on the iron oxide nanoparticles obtained in this work were synthesized by fast, simple and cost-effective co-precipitation technique and easily modified with oleylamine as the stabilizing agent. TEM studies reveal spherical shape with an 
a)

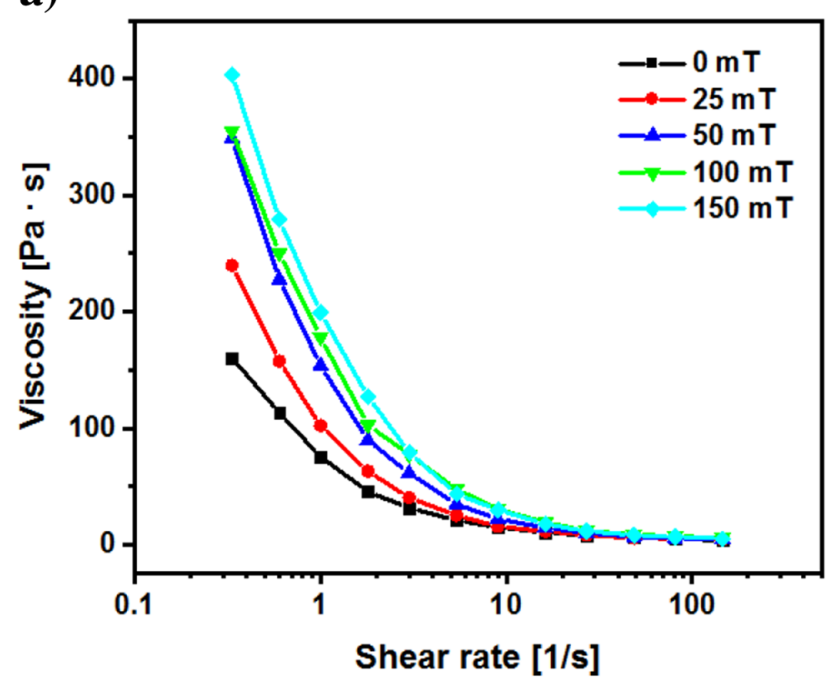

c)

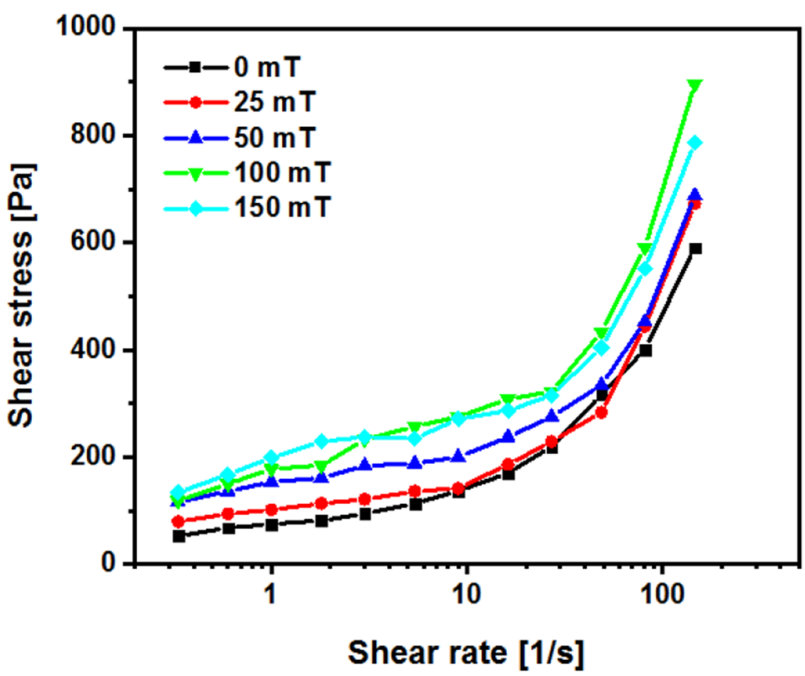

b)

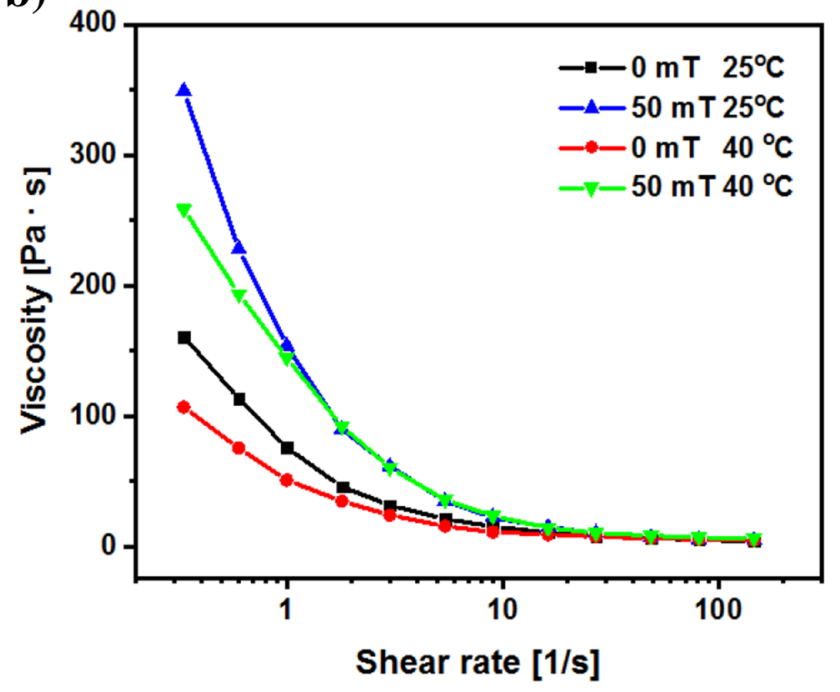

d)

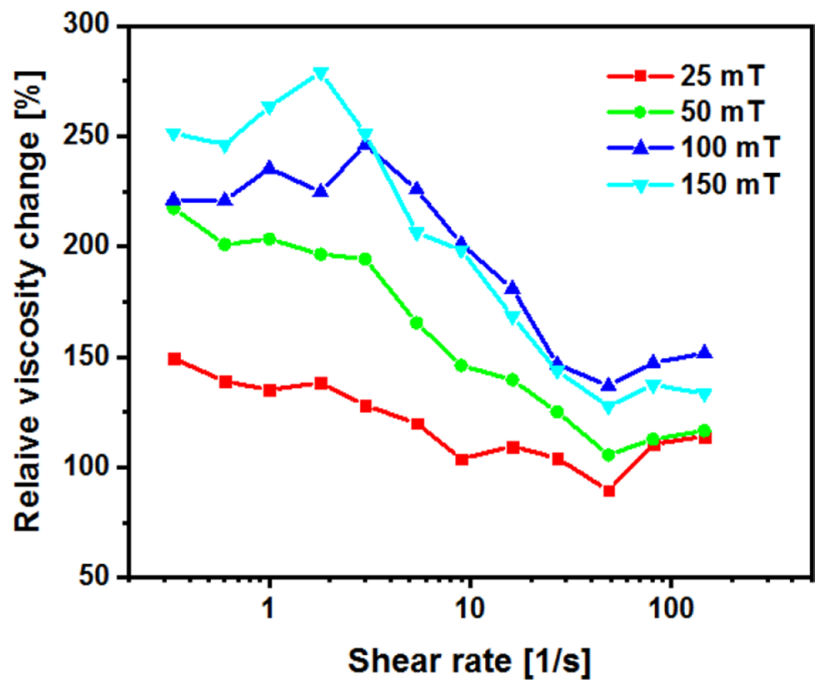

Fig. 14 Viscosity change in function of shear rate at a room temperature, $\mathbf{b} 40{ }^{\circ} \mathrm{C}$ and room temperature, $\mathbf{c}$ shear stress vs shear rate and $\mathbf{d}$ relative viscosity change vs shear rate. All measurements were performed in function of magnetic field

average size of about 10-15 nm before OA capping, while after SPION@OA creates homogeneous suspension with $100 \mathrm{~nm}$ size and spherical shape. Complex characterization confirms the successful capping of the magnetic core. Thermogravimetry analysis reveals that organic shell constitutes ca. $10 \%$ for the core of the conjugate mass. In the following studies, SPION@OA suspension was dispersed in the silicon oil, and two different MF fluids containing 65\% and $75 \%$ volume ratios were tested. An increase of concentration of capped nanoparticles in the MR fluid improves the stability of the fluid and performance against applied stress.

Split Hopkinson pressure bar modification from bar-bar into the bar-hollow system enabled to record of the transmitted wave during energy dissipation experiments with higher precision making it possible to record even tiny waves generated in the investigated material. Fluid prepared within this work responds reversibly and instantly to the stress occurring high yield stress, which makes it applicable in vibration reduction. Viscoelastic properties of $75 \% \mathrm{MRF}$ for high striker velocities are comparable with commercial LORD MRF-140CG containing $85.44 \%$ of magnetic particles in the fluid. MR fluid having a $75 \%$ volume ratio reveals a promising effect of dynamic energy dispersion, giving the opportunity to test it in brakes and dampers.

Acknowledgements M.O. would like to thank UOTT UW for support with grant funded under the Innovation Incubator 4.0 co-financed by Smart Growth Operational Programme 2014-2020, 4.4. E.K. and J.L. 
would like to thank Faculty of Physics, Polish Physical Society, and Warsaw City Hall for support with the project "Ochota na naukę". This work was supported with research grant Preludium UMO-2015/17/N/ ST8/02018 from National Science Centre. M.O. and E.K. would like to thank prof. Paweł Krysiński from the University of Warsaw for hosting in his laboratory facilities. M.O. would like to thank prof. Michael Giersig from the Institute of Fundamental Technological Research of the Polish Academy of Science for hosting her in his laboratory. This project is a part of a Science Embassy project.

Author contribution M. Osial, M. Nowicki, L. Frąś-conceptualization, data curation, investigation, formal analysis; E. Klejman-investigation; M. Osial—methodology, original draft, writing—review and editing; M. Osial and L. Frąś-funding acquisition; M. Osial—project administration, final review and editing.

\section{Declarations}

Conflict of interest Authors declare no conflict of interest. The founding has no role in the design of the study and in the collection, analyses, data interpretation, manuscript writing and decision to publish the results.

Open Access This article is licensed under a Creative Commons Attribution 4.0 International License, which permits use, sharing, adaptation, distribution and reproduction in any medium or format, as long as you give appropriate credit to the original author(s) and the source, provide a link to the Creative Commons licence, and indicate if changes were made. The images or other third party material in this article are included in the article's Creative Commons licence, unless indicated otherwise in a credit line to the material. If material is not included in the article's Creative Commons licence and your intended use is not permitted by statutory regulation or exceeds the permitted use, you will need to obtain permission directly from the copyright holder. To view a copy of this licence, visit http://creativecommons.org/licenses/by/4.0/.

\section{References}

Acharya S, Tak RSS, Singh SB, Kumar H (2020) Characterization of magnetorheological brake utilizing synthesized and commercial fluids. Mat Today: Proceedings 46(19):9419-9424. https://doi.org/ 10.1016/j.matpr.2020.03.061

An JS, Han WJ, Choi HJ (2017) Synthesis of hollow magnetite nanoparticles via self-assembly and their magnetorheological properties. Coll Surf a: Physicochem Eng Aspencts 535:16-23. https:// doi.org/10.1016/j.colsurfa.2017.09.019

Ashtiani M, Hashemabadi SH, Ghaffari A (2015) A review on the magnetorheological fluid preparation and stabilization. J Magnet Magnet Mat 375:716-730. https://doi.org/10.1016/j.jmmm.2014. 09.020

Ashour O, Rogers ACA, Kordonsky A (1996) Magnetorheological fluids: materials, characterization and devices. J Int Mat Sys Str 7:123-130. https://doi.org/10.1177/1045389X9600700201

Bica I (2006) Advances in magnetorheological suspension: production and properties. J Ind Eng Chem Col 12:501-515

Chae HS, Piao SH, Choi HJ (2015) Fabrication of spherical $\mathrm{Fe}_{3} \mathrm{O}_{4}$ particles with a solvothermal method and their magnetorheological characteristics. J Industr Eng Chem 29:129-133. https://doi. org/10.1016/j.jiec.2015.02.027

Chen W, Zhang B, Forrestal MJ (1999) A split Hopkinson bar technique for low-impedance materials. Experim Mechan 39:81-85
Espin MJ, Delgado AV, Rejon L (2005) Electrorheological properties of hematite/silicone oil suspensions under DC fields. J Non-Newt Fluid Mech 12:1-10. https://doi.org/10.1016/j.jnnfm.2004.08.004

Frąs LJ (2015) The Perzyna viscoplastic model in dynamic behaviour of magnetorheological fluid under high strain rates. Eng. Transac ISSN: 0867-888X 63(2):233-243

Frąś LJ, Pęcherski RB (2018) Modified split Hopkinson pressure bar for investigations of dynamic behaviour of magnetorheological materials. J Theor Appl Mechan 56(2018):323-328. https://doi. org/10.15632/jtam-pl.56.1.323

Galindo-Gonzalez C, Ponton A, Bee A, Chevalet J, Talbot D, Perzynski R, Dubois E (2016) Investigation of water-based and oilbased ferrofluids with a new magnetorheological cell: effect of the microstructure. Rheol Acta 55:67-81. https://doi.org/10.1007/ s00397-015-0892-5

Gawęda W, Osial M. Żuk M, Pękała M, Bilewicz A, Krysiński P (2020) Lanthanide-doped SPIONs bioconjugation with trastuzumab for potential antitumor activity and magnetic hyperthermia. Nanomat;10(2) https://doi.org/10.3390/nano10020288.

Guo YQ, Li Sun C, Xu ZD, Jing H (2018) Preparation and tests of MR fluids with CI particles coated with MWNTs. Fron Mater 5(50):1-8. https://doi.org/10.3389/fmats.2018.00050

Jolly RM, Carlson DJ, Munoz BC (1996) A model of the behaviour of magnetorheological materials. Smart Mater Struct 5:607-614

Jinaga R, Jagadeesha T, Kolekar S, Choi SB (2019) The synthesis of organic oils blended magnetorheological fluids with the fielddependent material characterization. In J Mol Sci 20:5766. https:// doi.org/10.3390/ijms20225766

Kciuk M, Turczyn R (2006) Properties and application of magnetorheological fluids. J Achiev Mat Manuf Eng 18:127-130

Kumar SK, Kumar A (2015) Geometric parameter optimization of magneto-rheological damper using design of experiment technique. Int J Mech Mater Eng 10(4):1-9. https://doi.org/10.1186/ s40712-015-0031-1

Kuman DR, Manoj D, Santhanalakshimi J (2014) Optimization of oleylamine- $\mathrm{Fe}_{3} \mathrm{O}_{4}$ /MWCNTs nanocomposite modified GC electrode for electrochemical determination of ofloxacin. J Nanosci Nanotech 14:5059-5069. https://doi.org/10.1166/jnn.2014.8676

Kumar JS, Paul PS, Raghunathan G, Alex DG (2019) A review of challenges and solutions in the preparation and use of magnetorheological fluids. J Mechan Mat Eng 14:13. https://doi.org/10. 1186/s40712-019-0109-2

Lim AS, Lopatnikov SL, Wagner NJ, Gillespie JW Jr (2010a) An experimental investigation into the kinematics of a concentrated hard-sphere colloidal suspension during Hopkinson bar evaluation at high stress. J Non-Newtonian Fluid Mech 165:1342-1350. https://doi.org/10.1016/j.jnnfm.2010.06.015

Lim AS, Lopatnikov SL, Wagner NJ, Gillespie JW Jr (2010b) Investigating the transient response of a shear thickening fluid using the split Hopkinson pressure bar technique. Rheol Acta 49:879-890. https://doi.org/10.1007/s00397-010-0463-8

Lu CH, Hu J, Shih WY, Shih WH (2016) Control of morphology, photoluminescence and stability of methylammonium lead bromide nanocrystals by oleylamine capping molecules. J Coll Interfaces Sci 484:17-23. https://doi.org/10.1016/j.jcis.2016.08.047

Muhhamed A, Yao XL, Deng ZC (2006) Review of magnetorheological (MR) fluids and its applications in vibration control. J Marine Sci App 5:17-29. https://doi.org/10.13140/RG.2.1.4079.6885

Osial M, Rybicka R, Pękała M, Cichowicz G, Cyrański MK, Krysiński P (2018) Easy synthesis and characterization of holmium-doped SPIONs. Nanomat 8(430):1-15. https://doi.org/10.3390/nano8 060430

Park BJ, Park CW, Yang SW, Kim HM, Choi HJ (2009) Core-shell typed polymer coated-carbonyl iron suspensions and their magnetorheology. J Phys Conf Ser 149:012078. https://doi.org/10.1088/ $1742-6596 / 149 / 1 / 012078$ 
Peng S, Wang C, Xie J, Sun S (2006) Synthesis and stabilization of monodisperse Fe nanoparticles. J Am Chem Soc 128:1067610677. https://doi.org/10.1021/ja063969h

Pręgowska A, Konowrocki R, Szolc T (2013) On the semi-active control method for torsional vibrations in electro-mechanical systems by means of rotary actuators with the magneto-rheological fluid. J Theor Appl Mech 51(4):979-992

Premalatha SE, Chokkalingham R, Mahendran M (2012) Magneto mechanical properties of iron based MR fluids. J Polym Sci 2(4):50-55. https://doi.org/10.5923/j.ajps.20120204.01

Rabbani Y, Hajinajaf N, Tavakoli O (2019) An experimental study on stability and rheological properties of magnetorheological fluid using iron nanoparticle core-shell structured by cellulose. J Thermal Anal Calorimetry 135:1687-1697. https://doi.org/10.1007/ s10973-018-7538-7

Rashid H, Mansoor MA, Haider B, Nasir R, Hamid SBA, Abdulrahman A (2020) Synthesis and characterization of magnetite nanoparticles with high selectivity using in-situ precipitation method. Separ Sci Techn 55:10-1215. https://doi.org/10.1080/01496395. 2019.1585876

Saha P, Mukherjee S, Mandal K (2019) Rheological response of magnetic fluid containing $\mathrm{Fe}_{3} \mathrm{O}_{4}$ nano structures. J Magnet Magnet Mat 484:3240328. https://doi.org/10.1016/j.jmmm.2019.04.055

Seo YP, Kwak S, Choi HJ, Seo Y (2016) Static yield stress of a magnetorheological fluid containing Pickering emulsion polymerized $\mathrm{Fe}_{2} \mathrm{O}_{3}$ /polystyrene composite particles. J Coll Interface Sci 463:272-278. https://doi.org/10.1016/j.jcis.2015.11.002

Shim J, Mohr S (2009) Using split Hopkinson pressure bar to perform strain compression tests on polyurea at low, intermediate and high strain rates. Int J Impact Eng 36:1116-1127. https://doi.org/10. 1016/j.ijimpeng.2008.12.010

Susan-Resiga D, Socoliuc V, Boros T, Borbáth T, Marinica O, Han A, Vékás L (2012) The influence of particle clustering on the rheological properties of highly concentrated magnetic nanofluids. J Coll Inter Sci 373:110-115. https://doi.org/10.1016/j.jcis. 2011.10.060

Wang Z, Jiang C, Huang R, Peng H, Tang X (2014) Investigation of optical and photocatalytic properties of bismuth nanospheres prepared by the facile thermolysis method. J Phys Chem C 118:1155-1160. https://doi.org/10.1021/jp4065505

Wang Y, Wang S, Xu C, Xuan S, Jiang W, Gong X (2016) Dynamic behavior of magnetically responsive shear-stiffening gel under high strain rate. Compos Sci Techn 127:169-176. https://doi.org/ 10.1016/j.compscitech.2016.03.009

Wang Y, Xie W, Wu D (2020) Rheological properties of magnetorheological suspension stabilized with nanocelluloses. Carbohydrate Polym 231(115776):1-9. https://doi.org/10.1016/j.carbpol.2019. 115776

Wereley NM, Chaudhuri A, Yoo JH, John S, Kotha S, Suggs A, Sudarshan TS (2006) Bidisperse magnetorheological fluids using $\mathrm{Fe}$ particles at nanometer and micron scale. J Intel Mat Syst Str 17:393-401. https://doi.org/10.1177/1045389X06056953

Wu J, Pei L, Huan S, Yan Q, Gong X (2016) Particle size dependent rheological property in magnetic field. J Magnet Manget Mat 408:16-25. https://doi.org/10.1016/j.jmmm.2016.02.005

Zhang JQ, Zhang J, Jing Q (2009) Effect of seven different additives on the properties of MR fluids. J Phys: Conf Ser 149:012086. https:// doi.org/10.1088/0964-1726/19/6/065006

Zhang JL, Srivastava RS, Misra RDK (2007) Core-shell magnetite nanoparticles surface encapsulated with smart stimuli responsive polymer: synthesis, characterization, and LCST of viable drugtargeting delivery system. Langmuir 23:6342-6351. https://doi. org/10.1021/la0636199

Zhu W, Dong X, Huang H, Qi M (2019) Iron nanoparticles-based magnetorheological fluids: a balance between MR effect and sedimentation stability. J Magnet Magnet Mat 491:165556. https://doi.org/ 10.1016/j.jmmm.2019.165556

Publisher's note Springer Nature remains neutral with regard to jurisdictional claims in published maps and institutional affiliations. 